\title{
Recursos educacionais abertos e atividades não-lineares: práticas contextualizadas baseadas na fronteira Jaguarão/Rio Branco
}

\author{
Recursos Educacionales Abiertos y Actividades No Lineares: prácticas \\ contextualizadas basadas en la frontera Jaguarão/Rio Branco
Open Educational Resources And Non-Linear Activities: contextualized practices based on the frontier Jaguarão/Rio Branco

\author{
Renan Cardozo Gomes da Silva ${ }^{1}$
}

\begin{abstract}
Resumo
Os Recursos Educacionais Abertos (REA) são materiais que estimulam o processo de ensino e de aprendizagem dos alunos e, geralmente, são encontrados em plataformas de domínio público (COSTA et al., 2016). Uma das plataformas que hospeda e possibilita a produção desses recursos se intitula Ensino de Línguas Online (ELO) e se destina ao ensino e aprendizagem de línguas. Este trabalho, financiado pela Coordenação de Aperfeiçoamento de Pessoal de Nível Superior (CAPES), objetiva discorrer sobre um curso de espanhol produzido na plataforma ELO, visando como público-alvo estudantes dos anos finais do ensino médio ou dos anos inciais de cursos de graduação que tenham como ênfase o ensino e aprendizagem de língua espanhola. A metodologia adotada, de cunho qualitativo, se ancorada em uma sequência de atividades destinada à produção de materiais didáticos intitulada Ciclo Recursivo (LEFFA, 2007) que se divide em 4 etapas: (1) Análise, (2) Desenvolvimento, (3) Implementação e (4) Avaliação. O curso produzido visa uma aprendizagem contextualizada, tendo como foco as regiões de fronteira, sobretudo a fronteira entre Jaguarão e Rio Branco, articulando o processo de ensino e de aprendizagem de língua espanhola e as Tecnologias Digitais da Informação e Comunicação (TDIC). Por fim, o curso, além de discutir sobre cultura e identidade, insere os alunos no campo das TDIC e da EaD, promovendo uma forma não-linear de aprender em rede.
\end{abstract}

Palavras-Chave: REA; ELO; Ensino de Espanhol; TDIC; Fronteira.

\section{Resumen}

Los Recursos Educacionales Abiertos (REA) son materiales que estimulan le proceso de enseñanza y de aprendizaje de los alumnos y, generalmente, son encontrados en plataformas de dominio público (COSTA et al., 2016). Una de las plataformas que posibilita está hospedaje y posibilita la producción de eses recursos recibe el nombre de Ensino de Línguas Online (ELO) y se destina a la enseñanza y aprendizaje de lenguas. Este trabajo, financiado por la Coordenação de Aperfeiçoamento de Pessoal de Nivel Superior (CAPES), objetiva discurrir sobre un curso de español elaborado en la plataforma ELO, visando como público objetivo los estudiantes de los años finales de la enseñanza media o de los años iniciales del curso de graduación que tengan como meta la enseñanza y aprendizaje de lengua española. La metodología adoptada, siguiendo la perspectiva cualitativa, se ancora en una secuencia de actividades destinada a la producción de materiales didácticos nombrada Ciclo Recursivo (LEFFA, 2007) que se divide en 4 etapas: (1) Análisis, (2) Desenvolvimiento, (3) Implementación e (4) Evaluación. El curso producido visa un aprendizaje contextualizada, teniendo como foco las regiones de frontera, sobretodo la frontera entre Jaguarão y Rio Branco, articulando el proceso de enseñanza y de aprendizaje de la lengua española y las Tecnologías Digitales de la Información y Comunicación (TDIC). Por fin, el curso, además de discutir sobre la cultura e identidad, insiere los alumnos en el campo de las TDIC y de la EAD, promoviendo una forma no linear de aprender en red.

Palabras claves: REA; ELO; Enseñanza de Español; TDIC; Frontera.

Abstract

\footnotetext{
1 Mestrando em Educação; Programa de Pós-graduação em Educação da Universidade Federal de Pelotas (PPGE-UFPEL); Pelotas, Rio Grande do Sul, Brasil; renancardozoo@ gmail.com.”
} 
Open Educational Resources (OER) are materials that stimulate the teaching and learning process of students and are generally found on public domain platforms (COSTA et al., 2016). One of the platforms that enables this hosting and production of these resources is called Ensino de Linguas Online (ELO) and is intended for language teaching and learning. This work, financed by the Coordenação de Aperfeiçoamento de Pessoal de Nível Superior (CAPES), aims to discuss a Spanish course developed on the ELO platform, targeting students in the final years of high school or the initial years of the graduation course whose goal is the teaching and learning of the Spanish language. The methodology adopted, following the qualitative perspective, is rooted in a sequence of activities aimed at the production of didactic materials called Ciclo Recursivo (LEFFA, 2007) which is divided into 4 stages: (1) Analysis, (2) Development, (3) Implementation and (4) Evaluation. The course produced aims at contextualized learning, focusing on the frontier regions, especially the border between Jaguarão and Rio Branco, articulating the teaching and learning process of the Spanish language and the Digital Information and Communication Technologies (DICT). Finally, the course, in addition to discussing culture and identity, inserts students in the field of TDIC and Distance Education, promoting a non-linear form of networked learning.

Key words: OER; ELO; Teaching of Spanish; DICT; Frontier.

\section{Introdução}

A Educação Aberta, conceito popularizado na década de 70, se refere às novas práticas de ensino e de aprendizagem que englobam diversos contextos. O termo "aberto(a)" remete a atividades didáticas que podem ser acessadas sem restrições e, geralmente, estão disponíveis em repositórios de código aberto para fins educacionais (OKADA, 2013, p. 22).

Partindo do conceito de abertura, despontam os Recursos Educacionais Abertos (REA), materiais que visam estimular o processo de ensino e de aprendizagem por meio de atividades, sequências didáticas ou cursos. Geralmente, os REA são encontrados em plataformas de domínio público que permitem adaptação e (re)compartilhamento, mediante a poucas ou nenhuma restrição (COSTA et al., 2016, p. 02).

Uma dessas plataformas, a qual utilizaremos nesse trabalho, intitula-se Ensino de Línguas Online (ELO) e destina-se ao ensino e aprendizagem de línguas como espanhol, português, inglês, italiano, alemão e etc. Segundo Leffa, seu idealizador, o ELO é "um programa de computador usado para a produção de arquivos digitais, geralmente incluindo texto escrito, imagem, som e vídeo" (LEFFA, 2006, p. 190). Além disso, o ELO oferece vários modelos de atividades para seus usuários criarem módulos e exercícios.

Tendo por base a produção de REA destinados ao ensino e aprendizagem de línguas, este trabalho, financiado pela Coordenação de Aperfeiçoamento de Pessoal de Nível Superior (CAPES), objetiva discorrer sobre um curso de espanhol produzido na plataforma ELO, visando como público-alvo estudantes dos anos finais do ensino médio ou dos anos inciais de cursos de graduação que tenham como ênfase o ensino e aprendizagem de língua espanhola. Em específico, pretendemos discutir, de maneira sucinta, os princípios teóricos que aportam os REA na plataforma ELO Cloud; relatar nossos procedimentos metodológicos; e, apresentar o curso elaborado. 
. A metodologia adotada, de cunho qualitativo, se ancorada em uma sequência de atividades destinada à produção de materiais didáticos intitulada Ciclo Recursivo (LEFFA, 2007) que se divide em 4 etapas: (1) Análise, (2) Desenvolvimento, (3) Implementação e (4) Avaliação. Nossos referenciais teóricos aludem à temática envolvida em nosso objetivo geral e sua explicitação queda-se organizada da seguinte maneira: 1) potencialidades dos REAs Santos (2013) e Canto (2014); 2) plataforma Elo Cloud como suporte para o ensino de línguas à distância - Canto (2014) e Leffa (2006); 3) seguimento de atividades que objetiva elaborar um instrumento de aprendizagem, doravante, Ciclo Recursivo - Leffa (2007).

Com vistas a alcançar nossos objetivos, e de fazer um percurso de escrita que melhor dê conta de traçar o percurso teórico-metodológico que construímos, nosso trabalho organizase em quatro seções, que se somam a esta introdução e uma seção de conclusão. São elas: 2 Educação Aberta e os REA, subdividida em 2.1 Fundamentos sobre REA e 2.2 ELO e os REA; 3 Primeiros Passos do Ciclo Recursivo, subdividido em 3.1 Análise e 3.2 Desenvolvimento; 4 Metodologia; 5 Análise de Dados e Apresentação do Curso, subdividida em 5.1 Primeiros Passos e 5.2 Nosotros Somos de la Frontera.

\section{Educação aberta e os REA}

No Brasil, antes do advento das tecnologias digitais, já haviam registros de educação aberta, a exemplo, podemos citar o sistema educacional via correspondência, rádio e televisão. Mais tarde, após a criação/evolução das mídias digital de informação e comunicação, por volta de 2005, criam-se as Universidades Abertas do Brasil (UAB) que, dentre os intuitos, tencionava expandir a educação superior em regiões, sobretudo, do interior do país (BRASIL, 2016). Para Santos, há diversas formas de se fazer educação aberta, desde que se considere os seus princípios basilares, ou seja, a Educação Aberta pode ser caracterizada como um grande guarda-chuva que engloba diferentes linhas teóricas e metodologias, sendo utilizada tanto na educação formal como na educação informal.

[...] termo educação aberta é utilizado atualmente no contexto dos chamados Recursos Educacionais Abertos (REA), trazendo consigo uma gama de novas práticas de ensino-aprendizagem que se popularizaram com o advento das tecnologias educacionais. O importante, porém, é compreendermos que o termo educação aberta é utilizado em contextos variados, que envolvem uma série de práticas, sendo algumas mais tradicionais e outras mais recentes; e que não é exclusivo à utilização de recursos educacionais abertos. Ao contrário. A utilização de recursos educacionais abertos é mais uma maneira de se fazer educação aberta. (SANTOS, 2012, p. 71) 
Relacionando com os REA, de acordo com Santos (2012), a Educação Aberta pode, ou não, fazer uso dos REA, entretanto, eles sempre farão uso dela, isso porque os REA “[...] podem ser considerados componentes (ou estratégias/práticas) da educação aberta, que é praticada atualmente dentro de uma perspectiva de compartilhamento de conteúdo digital com licença de uso aberta" (SANTOS, 2012, p. 83).

Com base nesses pressupostos, nas próximas seções, apresentaremos alguns fundamentos que explicam o que são os REA, como também apresentaremos uma plataforma aberta para a criação e utilização desses recursos.

\subsection{Fundamentos sobre REA}

Ao final da década de 90 e início dos anos 2000, iniciou um movimento que lançou um portal Web contendo uma série de recursos educacionais abertos, capitaneado pelo Instituto de Tecnologia de Massachusetts (MIT). Tal movimento foi chamado de OpenCourseWare (OCW), termo também aplicado aos conteúdos disponibilizados abertamente por universidades espalhadas pelo mundo via Internet. Após a propagação desse movimento, o MIT toma outra iniciativa, o MITx, que além dos materiais abertos, também disponibilizava cursos e ferramentas de aprendizagem (SANTOS, 2012, p. 21).

No Brasil, o OCW tardou a ser reconhecido e, mesmo com algumas publicações anteriores, um dos marcos de início das discussões sobre REA no país se dá em 2008, com o início do Projeto Brasileiro sobre Recursos Educacionais Abertos: desafios e perspectivas, financiado pelo Governo Federal, que objetivava "apropriar à realidade e às perspectivas brasileiras a discussão internacional acerca dos Recursos Educacionais Abertos (REA) e da Educação Aberta" (BRASIL, s/d). Mais tarde, também no Brasil, no estado de São Paulo, foi aprovada a política dos REAs por meio do PL 989/2011. Nela afirma-se que

[os] Recursos Educacionais desenvolvidos pela Administração Direta e Indireta Estadual deverão ser disponibilizados em sítio eletrônico destas instituições ou no Portal do Governo Estadual e licenciados para livre utilização, compreendendo a cópia, a distribuição, o download e a redistribuição, desde que observadas as seguintes condições:

I - preservação do direito de atribuição do autor;

II - utilização para fins não comerciais. (S ̃̃O PAULO, 2011).

Além disso, tais recursos possibilitam que materiais inertes se transformem em materiais flexíveis e adaptativos (CANTO, 2014), dando maior liberdade para o usuário. 
Conforme Canto (2014, p. 239), tal liberdade é dívida em quatro pontos, também chamados de "4Rs"; são eles: reusar, revisar, remixar e redistribuir. Segundo a autora, para que

[...]o uso desses materiais seja feito sem o infringimento dos direitos dos autores originais e para que o seu potencial seja realmente aproveitado em contextos específicos é importante que eles tenham uma licença livre, para que as liberdades de reuso, revisão, remix e redistribuição possam ser aplicadas. (CANTO, 2014, p. 240)

Essas licenças livres podem ser de três naturezas: a primeira, denominada "grau de abertura total”, permite aos materiais Reuso, Revisão, Remix e Redistribuição; a segunda permite somente o Reuso e a Redistribuição; e, a terceira permite somente o Reuso. Neste trabalho, apresentamos um curso configurado como REA e que contempla total abertura, ou seja, os "4Rs". Cabe salientar que para a construção do curso faremos uso da Revisão e da Redistribuição, mas deixaremos que usuários do ELO Cloud sejam livres para Reusarem, Remixarem e, novamente, Revisarem e Redistribuirem.

\subsection{ELO e os REA}

Por volta do ano 2001, na Universidade Católica de Pelotas, o professor Vilson Leffa lançou o projeto Ensino de Línguas Online (ELO). Nesse projeto, ainda em vigor, foi desenvolvido um sistema de autoria com vistas a "[...] reproduzir no espaço reduzido da tela do computador os três espaços fundamentais de uma sala de aula: o professor, o aluno e o conteúdo a ser aprendido - que são criados automaticamente pelo sistema de autoria proposto" (LEFFA, 2006, p. 188). Nesse momento inicial foi criado um protótipo, o ELO Desktop.

Nesse primeiro momento, o ELO era composto por cinco tipos de atividades: Sequência, que se destina à montagem de um texto seccionado; Cloze, lacunamento do texto; Eclipse, reconstrução de um texto encoberto; Múltipla-escolha, a partir de uma pergunta o aluno deve escolher a resposta correta; e, Exposição Dialogada, que se aproxima de uma aula tradicional. Segundo o professor

Cada uma dessas atividades apresenta um grau maior ou menor de interatividade com o aluno, com envolvimento também diferenciado para o papel do professor. Para fins de exposição dividimos as atividades em três níveis de interferência do professor: baixa, média e alta. (LEFFA, 2006, p. 190) 
O ELO desktop está ativo até os dias atuais, no entanto, no ano 2013 foi apresentada uma nova versão do sistema tendo como principais características a adaptabilidade e o compartilhamento (CANTO, 2014, p. 109). A nova versão do ELO, por ser totalmente online, adota a nomenclatura em inglês Cloud (nuvem), que se refere ao armazenamento de computadores e servidores, compartilhados e interligados por meio da internet (CANTO, 2014).

Diferente do anterior, o ELO Cloud possui dois tipos de usuários mediante cadastro, professores e alunos. Cada modalidade possui determinadas funções, e, além disso, caso o usuário não queira efetuar cadastro, pode realizar um breve tour pelo site. Conforme Canto,

[...] o ELO é um sistema de autoria interativo que o professor utiliza para elaborar atividades para seus alunos. Um sistema interativo, ainda segundo Leffa (2006), inclui quatro aspectos básicos: (1) o conteúdo que o professor deseja apresentar ao aluno; (2) a maneira como o conteúdo será apresentado; (3) os tipos de feedback que serão oferecidos; e (4) as ajudas durante o desempenho dos alunos por meio de dicas e pistas. Nesse sentido, é importante que o professor domine a ferramenta e conheça a sua estrutura para que possa preparar um conjunto de atividades e aplicá-las com seus alunos. (CANTO, 2014, p. 110-111)

Na sua nova versão, foram acrescentadas novas atividades que não eram suportadas pela versão Desktop. Atualmente, ele comporta oito tipos de atividade, são elas: Cloze, criação de textos lacunados; Memória, o usrário pode criar um jogo da memória; Eclipse, propõe que o aluno reconstrua textos; Composer, escrita livre; Vídeo, proporciona a inserção de vídeos disponíveis na rede; Hipertexto, permite a construção de páginas multimodais; Sequência, organização de textos; Quis, elaboração de perguntas de múltipla escolha e dialógica. Em tese, segundo Leffa,

[o] ELO é, em resumo, uma proposta de Recurso Educacional Aberto, com ênfase principal no adjetivo "aberto" em suas várias acepções, incluindo abertura de acesso livre, sem ônus para professores, alunos e escolas; abertura para rodar em diferentes sistemas, rumo à filosofia BYOD (Bring Your Own Device, Traga seu próprio dispositivo) e, finamente, abertura para adaptações, permitindo que as atividades possam ser desmontadas, modificadas em seus módulos e depois remontadas pelo professor. (LEFFA, 2014, p. 11)

A seguir, discutiremos a "sequência de atividades", pressuposto teórico-metodológico em que nos embasamos para o desenvolvimento da pesquisa, doravante, Ciclo Recursivo. Ainda, discorreremos, especificamente, sobre as duas etapas que adotamos para o desenvolvimento dessa pesquisa, a Análise e o Desenvolvimento. 


\section{Primeiros passos do ciclo recursivo}

O Ciclo Recursivo é uma sequência de atividades destinada a produção de materiais didáticos que envolve quatro momentos, são eles: (1) Análise, (2) Desenvolvimento, (3) Implementação e (4) Avaliação (LEFFA, 2007, p. 16-17). Cada um desses momentos referese a uma etapa da produção do material que culmina da sua avaliação, ou seja, no momento em que o professor avalia/reflete sobre o seu produto, elencando falhas e possíveis modificações.

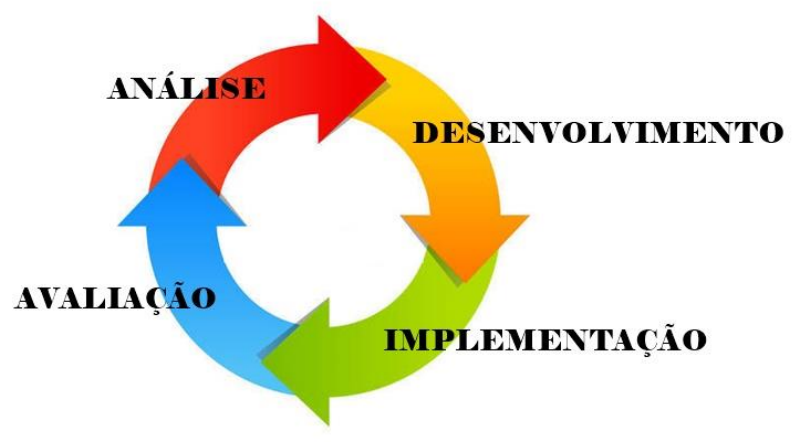

Figura 1 - Representação do Ciclo Recursivo.

Fonte: Elaborado pelo autor

Cabe salientar que nesse trabalho utilizamos somente dois momentos, a Análise e o Desenvolvimento, visto que por questões burocráticas, não tivemos a oportunidade de aplicar as atividades ao nosso público-alvo. A seguir, exporemos, mais detalhadamente, as etapas.

\subsection{Etapa de Análise}

A etapa da Análise leva em consideração as necessidades do aluno. Nela, o pesquisador verifica se o material que está sendo preparado/planejado contempla as competências e os conhecimentos prévios que os alunos possuem. Mais especificamente, segundo Leffa,

A análise parte de um exame das necessidades dos alunos, incluindo seu nível de adiantamento e o que eles precisam aprender. As necessidades são geralmente mais bem atendidas quando levam em consideração as características pessoais dos alunos, seus anseios e expectativas, preferência por um ou outro estilo de aprendizagem. (LEFFA, 2007, p. 17) 
Nessa perspectiva, é importante que o professor conheça e seja ciente dos saberes já adquiridos pelo aluno, e, a partir deles, pensar em atividades que ativem os seus conhecimentos prévios. Assim, levando em conta a construção de uma proposta didática, tais questões tornam o processo de ensino e de aprendizagem mais significativo. Para Leffa,

\begin{abstract}
[o] material a ser produzido deve oferecer ao aluno a ajuda que ele precisa no grau exato de seu adiantamento e de suas necessidades, preenchendo possíveis lacunas. A análise inicial das necessidades deve ser capaz não só de estabelecer o total das competências a serem desenvolvidas, mas também descontar dessas competências o que o aluno já domina. (LEFFA, 2007, p. 17)
\end{abstract}

Após essa etapa, passamos para o Desenvolvimento que se refere a elaboração das atividades a partir do que foi analisado na etapa anterior, articulando conteúdos linguísticos, comunicativos e culturais.

\title{
3.2. Etapa de Desenvolvimento
}

Com a finalização da Análise, Leffa (2007) orienta que se deve traçar objetivos para encaminhar a produção da atividade. Nessa etapa, o pesquisador delimita os objetivos que o direcionarão para o que deve ser realizado pelos alunos e pelo professor na atividade em construção e, em seguida, aplicá-la. Conforme o pesquisador,

[a] etapa do desenvolvimento parte dos objetivos que são definidos depois da análise das necessidades. A definição clara dos objetivos dá uma direção à atividade que está sendo desenvolvida com o uso do material. Ajuda a quem aprende porque fica sabendo o que é esperado dele. Ajuda a quem elabora o material porque permite ver se a aprendizagem está sendo eficiente, facilitando, assim, a avaliação. (LEFFA, 2007, p. 17)

Na elaboração dos objetivos, o professor deve prever se sua atividade terá longa ou curta apresentação, visto que, para aplicações longas, deve-se elaborar um objetivo geral, e, para aplicações curtas, somente objetivos específicos. Assim, Leffa (2007, p. 18) orienta que os objetivos de aprendizagem possuem três componentes principais, sendo eles: "(1) as condições de desempenho; (2) o comportamento que o aluno deve demonstrar (expresso por um verbo); (3) o critério de execução da tarefa" (LEFFA, 2007, p. 18).

Após a definição dos objetivos, os próximos passos são os conteúdos que serão abordados, a abordagem que será seguida, as atividades que serão aplicadas, os recursos que serão utilizados e o ordenamento das atividades. 
Vale, mesmo que não seja abordado nesse trabalho, explicar, rapidamente, as outras etapas: a Implementação que se volta a três situações, “(1) o material vai ser usado pelo próprio professor, (2) o material vai ser usado por outro professor, (3) o material vai ser usado diretamente pelo aluno sem presença de um professor" (LEFFA, 2007, p. 34), a partir dessas três situações o elaborador do material escolhe uma estratégia de produção. A etapa da Avaliação, se refere ao modo que o material será avaliado, podendo dar-se de maneira formal ou informal (LEFFA, 2007, p. 38), dependendo da maneira como o profissional idealiza o material.

Em suma, a produção de materiais voltados ao ensino é, segundo Leffa (2007, p. 15) "[...] uma seqüência de atividades que tem por objetivo criar um instrumento de aprendizagem". Nesse caso, o Ciclo Recursivo ampara o profissional na elaboração desse instrumento por meio dos quatro momentos anteriormente abordados, e, após a avaliação, último momento, é feita uma nova Análise, e o Ciclo poderá ser reiniciado novamente (LEFFA, 2007, p. 16).

\section{Metodologia}

Seguindo os postulados de Bogdan e Biklen (1994), essa pesquisa se classifica como uma investigação qualitativa, em que a fonte direta de dados se dá em ambiente natural. Seguindo essa concepção, acreditamos que "[...] as acções podem ser melhor compreendidas quando são observadas no seu ambiente habitual de ocorrência" (BOGDAN e BIKLEN, 1994, p. 48). Logo, a metodologia se organiza nos seguintes momentos:

O primeiro momento diz respeito às observações realizadas em uma turma de primeiro semestre do Curso de Letras Português-Espanhol da UNIPAMPA - campus Jaguarão, no período noturno, com, cerca de, 25 alunos. Nessa etapa, verificamos que a turma ${ }^{2}$ se divide entre alunos que vieram de outros Estados brasileiros e alunos gaúchos que, em sua maioria, são naturais de Jaguarão e Arroio Grande. Também direcionamos o nosso olhar para a metodologia e para as práticas desenvolvidas pela professora, a qual, divide as aulas por temáticas, em que são relacionados conteúdos gramaticais, práticas orais e auditivas. O conteúdo da disciplina abarca conhecimentos primários da língua, como: alfabeto, partes do corpo, apresentações, saudações, comidas e etc. Por conta disso, a professora traz outros

\footnotetext{
${ }^{2}$ Vale ressaltar que, na UNIPAMPA, a turma do primeiro semestre do Curso de Letras se divide em dois grupos na disciplina de Língua Espanhola I, de modo a proporcionar ao professor maiores possibilidades de ensino e aprendizagem aos alunos.
} 
elementos que possibilitem ao aluno adquirir uma visão mais ampla da relevância política e social da língua espanhola no cenário mundial.

O segundo momento da pesquisa foi destinado à aplicação de questionários, no qual, primeiramente aplicamos aos alunos, com vistas a investigar a sua motivação em estudar espanhol, as dificuldades com o processo de ensino e aprendizagem da dita língua e a sua opinião sobre educação a distância; posteriormente aplicamos o questionário à professora titular do componente curricular, buscando inferir seu ponto de vista a respeito da utilização das Tecnologias Digitais da Comunicação e Informação (TDIC) em sala de aula e as possíveis contribuições que essas práticas podem trazer aos alunos; por último, aplicamos um questionário à Coordenação de Curso, para investigar questões que se destinam ao estímulo que o Núcleo Docente Estruturante dá para o uso das TDIC em classe, bem como conhecer as normativas existentes que respaldam o professor para desenvolver atividades a distância e em quais circunstâncias os professores podem se valer de tais práticas.

No terceiro momento, em que nos ancoramos na etapa do Desenvolvimento (LEFFA, 2007), nos debruçamos na construção de um curso online na plataforma ELO Cloud. Ressaltamos que o curso foi elaborado em licença aberta e contempla alguns conteúdos da disciplina, mas, seu foco se dá no estímulo e promoção das TDICs como ferramenta de ensino e em questões culturais da região fronteiriça em que a Universidade se aloca.

\section{Análise de dados e apresentação do curso}

A seguir, subdividiremos esta seção em dois momentos: o primeiro, no qual, relataremos os dois primeiros momentos da pesquisa (observação e aplicação dos questionários); e, no segundo, descreveremos o terceiro momento, ou seja, a produção do curso.

\subsection{Primeiros Passos}

Seguindo os postulados de Leffa (2007), primeiramente realizamos observações no componente curricular Língua Espanhola 1, primeira disciplina de Espanhol ofertada no Curso de Letras da UNIPAMPA, campus Jaguarão, no qual buscamos examinar os conhecimentos que os alunos tinham da/sobre a língua espanhola e as competências que foram desenvolvidas no decorrer das aulas. 
Realizamos um total de 20 horas de observação, no qual a professora desenvolvia atividades por meio de temáticas que eram escolhidas a partir das curiosidades que os estudantes levantavam em sala. A exemplo podemos citar alguns temas como: Español en nuestro mundo; apresentar de biografias de alguma personalidade famosa do mundo hispano/latino americano; a importância da cultura espanhola; nacionalidades; linguagem formal e informal.

Durante as observações podemos notar algumas especificidades que nos auxiliaram na construção do curso. Durante as aulas, vimos o quanto a Espanha é prestigiada, pois, na maioria dos trabalhos e nos materiais utilizados, a variante que predominava era a peninsular, ocasionando, assim, um desprestigio às variantes latinas e, sobretudo, ao país qual fazemos fronteira, Uruguai.

Com relação aos materiais utilizados pela professora, com base nos postulados de Leffa (2007), vemos que eles vão ao encontro com o nível dos alunos e, trabalhar com materiais produzidos na Espanha é uma forma de acionar os conhecimentos prévios dos mesmos, já que eles estão mais familiarizados com esse espaço.

No segundo momento da pesquisa, aplicamos questionários aos alunos investigados, à professora do componente curricular e à Coordenação de Curso. Referente ao primeiro questionário, destinado aos alunos, recebemos 15 respostas, no qual, com base nas respostas obtidas, podemos observar que os estudantes possuem motivação em estudar língua espanhola e acreditamos que essa motivação seja reflexo das aulas e dinâmicas realizadas. Ademais, também podemos destacar a importância de expor os alunos a práticas mediadas pelo computador, visto que muitos contestaram que tais propostas podem promover uma maior aproximação com a língua.

Passando para o segundo e o terceiro questionário, aplicado à professora e a coordenação do curso, podemos delegar que ambas concordam com as práticas a distância, visto que são alunos oriundos da Era da Informação e tais práticas podem auxiliá-los a complementar a baixa carga-horária dedicada à língua espanhola na grade curricular do curso.

\subsection{Nosotros somos de la frontera}

Partindo das orientações dadas por Leffa (2007) sobre a etapa do Desenvolvimento, construímos um curso para proporcionar aos alunos um primeiro contato atividades digitais. Por conta disso, construímos materiais explicativos e que, possivelmente, não gerarão dúvidas durante a execução. Conforme abordado anteriormente, durante a sua construção não 
realizamos a implementação de todos os "4 Rs" (CANTO, 2014, p. 110-111), fazemos uso da Revisão e Redistribuição, mas deixamos a total abertura para os demais usuários Reusarem, Remixarem e, novamente, Redistribuirem e Revisarem.

O objetivo das atividades do curso é explorar algumas questões culturais das regiões de fronteira, sobretudo da fronteira Jaguarão-Rio Branco. Este objetivo surgiu devido às observações, relatadas na subseção anterior, visando desmistificar o prestígio linguístico dado à Espanha e sensibilizar o olhar dos alunos para a nossa região, fronteira entre Brasil-Uruguai.

O curso nomeado "Nosotros Somos de la Frontera"3, foi construído em quatro módulos e, em cada módulo, são trabalhadas diferentes atividades e habilidades, perfazendo um total de, aproximadamente, doze horas/aula. Ademais ele foi construído separadamente com o intuito de ser não-linear e possibilitar que seja utilizado como o professor achar mais pertinente.

Durante as atividades, contemplamos alguns conteúdos do componente curricular observado, exercitando, sobretudo, a escrita, a leitura e a audição, três destrezas que, a partir das observações e das respostas da professora no questionário, acreditamos que precisam ser exploradas devido às dificuldades apresentadas pelos alunos.

Em resumo, o primeiro módulo (Módulo 1) foca em questões gerais do espaço fronteiriço, estimulando o aluno a refletir sobre a fronteira para além de um espaço geográfico; o segundo módulo (Módulo 2) direciona ao espaço fronteiriço Jaguarão-Rio Branco a partir da literatura; o terceiro módulo (Módulo 3) visa as peculiaridades e interações entre as duas cidades; o quarto módulo (Módulo 4) finaliza o estudo apresentando um fenômeno linguístico recorrente nas fronteiras, o portunhol. A seguir, apresentaremos, mais detalhadamente, cada módulo do curso:

\section{Módulo 1}

\footnotetext{
${ }^{3}$ Par consultar o curso acesse <http://www.elo.pro.br/cloud/>, faça o cadastro e busque "Nosotros Somos de la Frontera". Ou acesse através dos seguintes links:

Módulo 1: <http://www.elo.pro.br/cloud/aluno/atividade.php?id=2432\&limpa_score=1 > ;

Módulo 2: <http://www.elo.pro.br/cloud/aluno/atividade.php?id=2472\&limpa_score=1>;

Módulo 3: <http://www.elo.pro.br/cloud/aluno/atividade.php?id=2434\&limpa_score=1 > ;

Módulo 4: 〈http://www.elo.pro.br/cloud/aluno/atividade.php?id=2480\&limpa_score=1〉.
} 


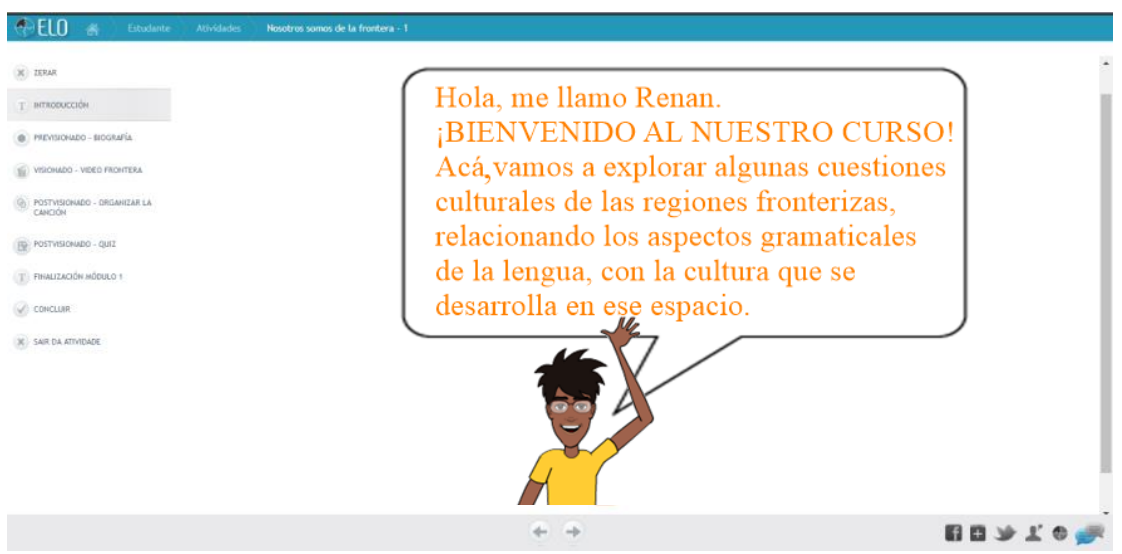

Figura 3 - Página inicial do primeiro módulo do curso Nosotros Somos de la Frontera.

Fonte: http://www.elo.pro.br/cloud/aluno/atividade.php?id=2432\&limpa_score=1

O primeiro módulo do curso se destina à introdução da temática que objetivamos explorar. Além disso, como será o primeiro contato dos alunos com o ELO Cloud, construímos um módulo simples e que exige conhecimentos básicos de Internet. Nele, trabalhamos a partir da perspectiva de pré-visionado, visionado e pós-visionado (MANZANERA, 2013), buscando tratar do conceito de fronteira de maneira ampla. Vale ressaltar que, durante a descrição das atividades de cada curso, evidenciaremos que tipo de atividade do ELO Cloud foi utilizada.

Iniciamos o curso utilizando a ferramenta Texto, construindo uma introdução para situar os alunos no curso e contextualizá-los sobre o que será tratado. Após a dita introdução, passamos para a primeira atividade, em que apresentamos o cantor e escritor Jorge Drexler, disponibilizando a sua biografia lacunada e, utilizando a atividade Eclipse, pedimos aos alunos que preenchessem as lacunas com os verbos destacados no pretérito perfeito simples.

Após essa atividade, fazendo uso da atividade Vídeo, disponibilizamos um vídeoclipe da música "Frontera", também de Drexler, para que os alunos escutassem e compreendessem o seu sentido e, posteriormente, usando a atividade Sequência, pedimos aos alunos que organizassem a letra da música que estava desorganizada.

Para finalizar esse módulo, utilizando a atividade Composer, elaboramos seis questões para verificar a compreensão dos alunos sobre a música e, além disso, exporem o seu primeiro olhar sobre a fronteira. São elas: 1.) ¿Do qué trata la canción?; 2.) ¿Donde está ubicada la casa del cantante?; 3.) ¿Quiénes son los padres del yo lírico?; 4.) ¿A partir de la letra de la cancíón, cómo podemos definir la frontera?; 5.) ¿Porqué "las fronteras se mueven como las banderas"?; 6.) ¿Todas las fronteras son iguales? Justífica tu respuesta. Ao fim, utilizamos, 
novamente, a ferramenta Texto para concluir o módulo e para dar as coordenadas para a sequência do curso, o módulo 2.

Este primeiro módulo, desempenha a função de potencializador, para mostrar para aos alunos diferentes modos de aprender em cursos a distância, além problematizar algumas questões sobre a fronteira. Ressaltamos que, no presente curso, pensamos a fronteira enquanto espaço hibrido, intercultural e vivo.

Módulo 2

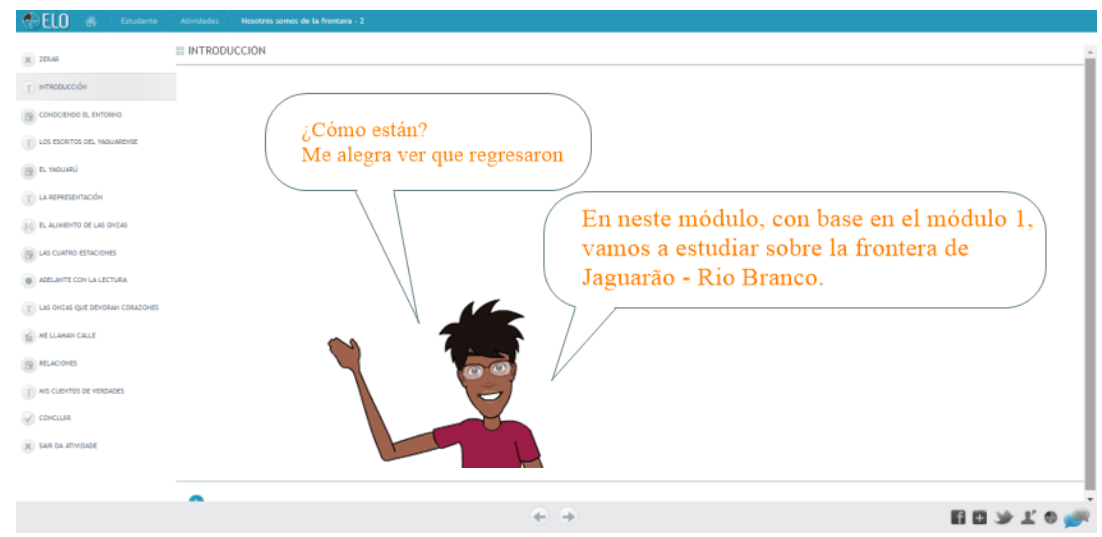

Figura 3 - Página inicial do segundo módulo do curso Nosotros Somos de la Frontera.

Fonte: http://www.elo.pro.br/cloud/aluno/atividade.php?id=2472\&limpa_score=1

Diferentemente do primeiro módulo, no segundo delimitamos o espaço trabalhado situando o aluno na fronteira Jaguarão-Rio Branco e, já passado o primeiro contato com a plataforma, nesse módulo, construímos mais atividades. Nosso fio condutor é um conto escrito pelo escritor jaguarense Aldyr Garcia Schlee; a partir do conto e dos seus possíveis sentidos, pensamos as atividades.

Primeiramente, assim como no primeiro módulo, utilizamos a ferramenta Texto para introduzir os alunos no que será abordado nesse curso. Após, empregando a atividade Composer, elaboramos duas questões para iniciar as atividades. São elas: 1.) Schlee trata la frontera como una línea imaginaria. Comente tal expresión; 2.) A partir de una investigación en sitios web, haz un párrafo resumiendo la leyenda del yaguarú. A primeira nos situa espacialmente e nos faz pensar como se dão as relações fronteiriças em Jaguarão-Rio Branco e outra nos remete à construção do mito fundador da cidade.

Após responderem as perguntas, utilizando a ferramenta Texto, apresentamos o conto que será trabalhado e disponibilizamos o primeiro parágrafo. O conto intitula-se "As Grandes 
Onças Bravas", no qual realizamos uma protocolação a fim de criar entrecruzamentos com atividades de cunho reflexivo. O primeiro parágrafo do conto traz a descrição dos Yaguarones e, indo ao encontro com essa descrição, passamos para a próxima atividade em que, utilizando a atividade Composer, pedimos que os alunos relacionassem o Jaguarú encontrado nas lendas (módulo 1) e os Yaguarones do conto. Posteriormente, ainda relacionado ao primeiro parágrafo, por meio da atividade Texto, trazemos uma pintura que está no Hall da Unipampacampus Jaguarão, a fim de mostrar outra leitura do Jaguarú. Em seguida disponibilizamos o segundo parágrafo do conto.

No seguimento do conto, o narrador fala do alimento dos Yaguarones: o coração de suas vítimas. Através da questão da alimentação, mobilizada pelo conto, elaboramos, utilizando a atividade Organizador, uma atividade para organizar as partes do corpo com o seu respectivo nome e, em seguida, por meio da atividade Composer, perguntamos para os alunos em qual estação do ano os jaguarões costumavam se alimentar, o que deveria ser justificado com argumentos/marcas da própria narrativa.

Mais adiante, fazendo uso da atividade Eclipse, disponibilizamos outro fragmento do conto mas, concomitantemente com a leitura, os alunos precisam completar lacunas do conto com artigos definidos e indefinidos. Após, empregando a ferramenta Texto, disponibilizamos outro fragmento da narrativa e, com a ferramenta Vídeo, disponibilizamos um vídeoclipe da canção "Me Llamo Calle" do cantor Manu Chao, a partir do qual, mediante a leitura e o visionado do vídeoclipe, realizamos outra atividade Composer, solicitando aos estudantes que façam uma discussão sobre a contranarrativa do mito fundador, em Schlee, que aloca as onças bravas, o Jaguarú, como as prostitutas que viviam na zona portuária do Rio Jaguarão. Para finalizar este módulo, usamos a ferramenta Texto para concluir o conto.

Com esse módulo, além de fazermos uso das potencialidades do ELO Cloud, fazemos com que os alunos naveguem e façam buscas de outros elementos que vão além do que está posto no curso; assim, demonstramos, também, que a EAD não se dá somente em um espaço fixo de aprendizagem, o estudante deve buscar outras informações e complementar sua formação em espaços que vão além das plataformas canônicas, a exemplo, o Moodle (XAVIER, 2006). Com esse módulo, direcionamos a visão dos alunos por meio das potencialidades das TDIC, aliadas ao uso da literatura, apresentação de escritores, pesquisas na rede e em outros espaços além do ELO.

\section{Módulo 3}




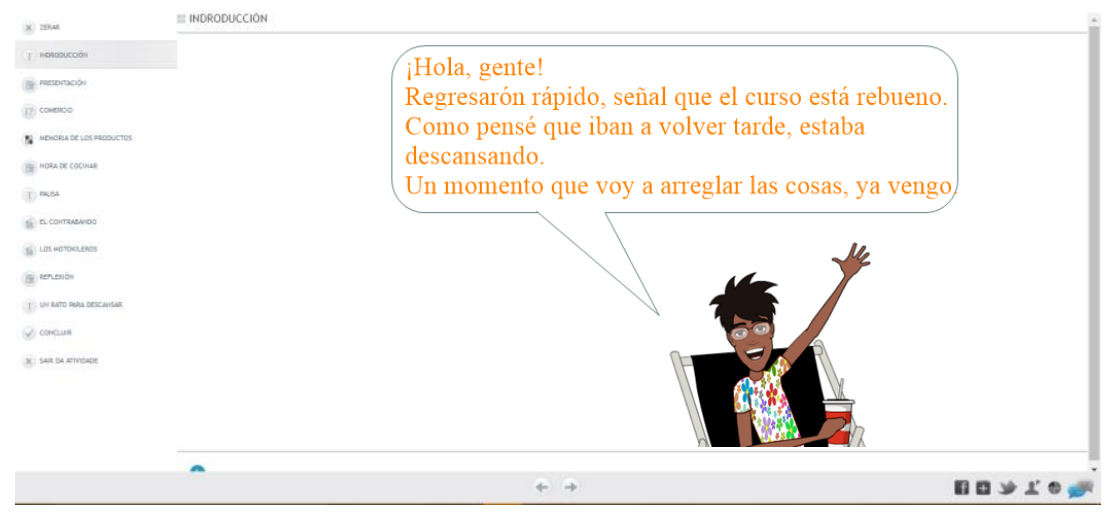

Figura 4 - Página inicial do terceiro módulo do curso Nosotros Somos de la Frontera. Fonte: http://www.elo.pro.br/cloud/aluno/atividade.php?id=2434\&limpa_score=1

No módulo três, o nosso foco foi o comércio de fronteira e suas peculiaridades. Para a continuidade das atividades, primeiramente, empregamos a ferramenta Texto, para contextualizar o que será tratado no módulo. Logo, na primeira atividade, fazendo uso da atividade Composer, pedimos aos alunos que elaborem um texto de apresentação de JaguarãoRio Branco, expondo o seu olhar sobre esse espaço. Após essa apresentação, a próxima atividade é um Quiz com cartazes de estabelecimentos comerciais que, por meio das imagens, os estudantes são provocados a identificar qual lado da ponte eles pertencem - Jaguarão ou Rio Branco. Nessa atividade, a maioria dos cartazes trazem "mesclas" entre o português e o espanhol, de modo a nos fazer refletir para que público ele se destina, visto que, a maioria dos comércios selecionados estão alocados na zona comercial de Rio Branco e visam o turista brasileiro.

$\mathrm{Na}$ atividade seguinte, elaboramos um Jogo da Memória, no qual foram selecionados alimentos que compunham o catálogo do supermercado "El Dorado", único supermercado de Rio Branco, assim os alunos podem revisar ou conhecer o nome dos produtos. A seguir, fazendo uso da um atividade Composer, e fazendo uso de alguns cartazes de restaurantes e nomes de alimentos, solicitamos a elaboração de uma receita e, para isso, os estudantes tem à sua disposição, para consulta, o catálogo do supermercado disponibilizado em hiperlink e um cardápio que está na introdução da atividade.

Em sequência, usando a ferramenta Texto, propomos uma pausa para assistir dois vídeos. O primeiro discorre sobre a operação Fronteira Sul, realizada pelo exército brasileiro para aprender drogas, veículos e armas, contrabandeados pelas fronteiras no ano de 2011 e o segundo fala sobre os "Motokileros", que são pessoas que cruzam a fronteira para comprar alimentos no Brasil para comercializar no Uruguai ou suprir suas residências. A partir desses 
dois vídeos, usamos a atividade Composer para propor uma reflexão sobre as práticas de contrabando, pedindo um posicionamento subjetivo dos alunos a respeito dessa prática. A seguir, concluímos o módulo com a ferramenta Texto.

\section{Módulo 4}

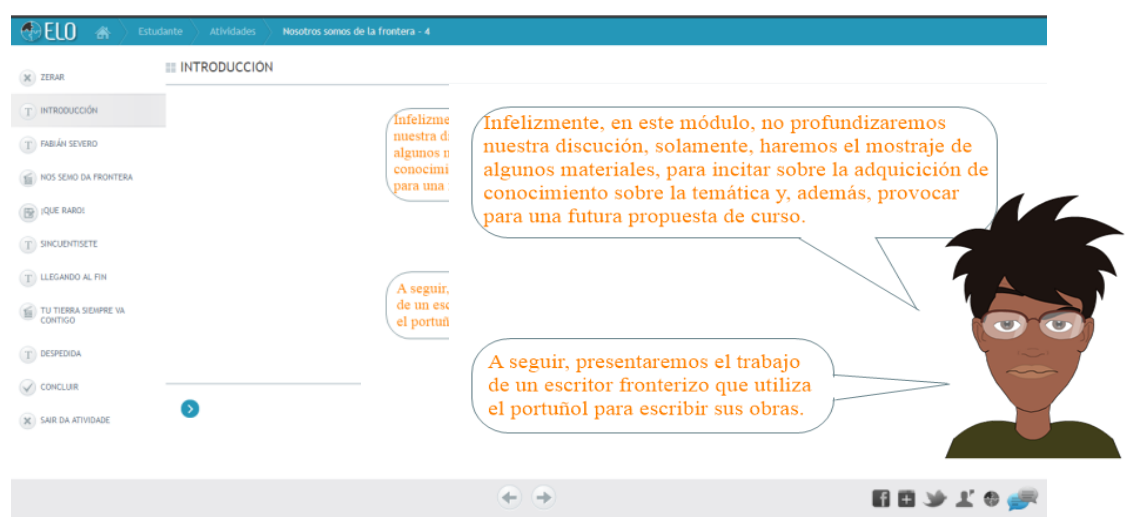

Figura 5 - Página inicial do quarto módulo do curso Nosotros Somos de la Frontera.

Fonte: http://www.elo.pro.br/cloud/aluno/atividade.php?id=2480\&limpa_score=1

No último módulo, devido à carga-horária que nos propomos a cumprir, doze horas, não pudemos nos estender. Então, resolvemos fazer uma breve explanação sobre um fenômeno bastante discutido em regiões fronteiriças, o portunhol. Como base para essas discussões, nos valemos dos escritos de Fabían Severo, o qual possui uma extensa obra composta de poemas e narrativas escritas em portunhol.

Como nos outros módulos, realizamos uma introdução por meio da ferramenta Texto. Posteriormente, fazendo uso da mesma ferramenta, apresentamos o escritor e anunciamos que nossa próxima atividade seria escutar o áudio do poema chamado "Sincuentisete", áudio foi disponibilizado através da ferramennta Vídeo. Após o áudio, levantamos uma problemática sobre o poema, perguntando, por meio da atividade Composer, como os estudantes se posicionam frente ao portunhol.

Posteriormente, com a ferramenta Texto, disponibilizamos o poema na íntegra e, com a mesma ferramenta, anunciamos um recital de Severo juntamente com o cantor Ernesto Díaz, recital que resume o nosso objetivo geral que é explorar algumas questões culturais das regiões de fronteira. Em seguida, com o auxílio da ferramenta Texto, realizamos a conclusão do curso e pedimos aos alunos que deixem uma avaliação para que possamos analisar os 
comentários e voltar às etapas do Ciclo Recursivo, realizando, assim, outro Ciclo (LEFFA, 2007).

Dada a apresentação do curso, acreditamos que ele oferecerá diferentes aprendizados aos alunos que venham a ser seu público-alvo, tanto no que se refere aos conteúdos da disciplina, aquisição de conhecimento sobre outros espaços - fronteira, como no manejo das potencialidades das TDIC e da EAD. Conforme Okada (2013, p.22) os REA colaboram para garantir um resultado positivo no processo de ensino e de aprendizagem ao qual se destina, além disso, enriquecem a aprendizagem colaborativa em paralelo com a construção de conhecimentos.

Como já abordamos anteriormente, os estudantes possuem pouco tempo, em sala de aula, para se dedicarem à aprendizagem de uma língua estrangeira e, assim, devem recorrer a outros meios para fazê-lo. Segundo Canto (2014, p. 16), as "TIC tem proporcionado diferentes recursos que podem ser utilizados na construção e elaboração de materiais digitais voltados ao ensino de línguas". Nesse ponto é que cursos como esse se tornam relevantes, visto que estão disponíveis online, não necessitam da presença do professor para a condução das atividades e auxiliam a desenvolver as habilidades de escrita, compreensão leitora e compreensão auditiva.

De modo geral, o curso, além de trazer as contribuições para o qual fora construído, ele insere os alunos no campo das TDICS e da EAD, promovendo uma forma não-linear de aprender (XAVIER, 2006), visto que, em ambiente virtual, o aluno pode navegar por outras páginas, buscar informações complementares e, ao mesmo tempo, realizar as atividades que lhe foram propostas.

\section{Conclusão}

O objetivo dessa pesquisa foi o de desenvolver um curso de espanhol aberto na plataforma ELO Cloud. Para isso, desenvolvemos uma breve discussão teórica sobre as potencialidades dos REAs e do ELO Cloud, apresentamos uma sequência para a produção de materiais didáticos, denominada, por Leffa (2007), Ciclo Recursivo, expusemos a metodologia adotada, descrevemos, brevemente, as aulas observadas, analisamos os questionários aplicados e, por fim, apresentamos o curso elaborado com base nas análises realizadas durante a pesquisa. 
Com a elaboração desse curso, podemos nos acercar das discussões que norteiam a educação aberta e os REA, visto que eles fazem parte de um movimento de compartilhamento de materiais, ideias, propostas e metodologias.

Durante as observações das aulas, notamos o quanto os países hispânicos da América Latina, sobretudo, da região do MERCOSUL, são desvalorizados. A UNIPAMPA - campus Jaguarão, está localizada em uma zona fronteiriça em que as relações entre as duas cidades são contínuas, inclusive no interior da Universidade, devido o ingresso de alunos fronteiriços. Por conta disso, acreditamos que esse espaço deve ser descortinado.

Esta pesquisa ainda não está encerrada, sua continuação é destinada à aplicação do curso que aqui propomos. Esperamos que ele seja utilizado e que os professores possam se valer de tais recursos e, assim como nós, contribuam para a disseminação da educação aberta e de REA, valorizando, principalmente, aspectos da sua cultura, dos alunos e da cultura dos Outros.

\section{Referências}

COSTA, R. A. et al. Contribuindo com o Estado da Arte Sobre Recursos Educacionais Abertos para o Ensino e a Aprendizagem de Línguas no Brasil. Veredas Online, v. 20, n, 1, p. $1-20,2016$.

BRASIL. Recursos Educacionais Abertos. Disponível em: < http://www.rea.net.br/site/>. Acesso em: 05 mar. 2017.

BOGDAN, R.; BIKLEN, S. Investigação Qualitativa em Educação: uma introdução à teoria e aos métodos. Porto: Proto Editora, 1994.

CANTO. C. G. S. O Desenvolvimento e a Implementação de uma Webquest Interativa e Adaptativa Destinada ao Ensino de Línguas. Tese (Doutorado) - Universidade Católica de Pelotas, 2014.

LEFFA, V. J. Uma ferramenta de autoria para o professor: o que é e o que faz. Letras de Hoje, Porto Alegre, v. 41, n. 144, p. 189-214, 2006.

Como produzir materiais para o ensino de línguas. In: LEFFA, Vilson J. (Org.). Produção de materiais de ensino: teoria e prática. 2 ed. Pelotas: EDUCAT, 2007, p. $15-41$.

Gamificação adaptativa para o ensino de línguas. In: Congresso Ibero-Americano de Ciência, Tecnologia, Inovação e Educação. Buenos Aires. Anais, 2014, p. 1-12.

Uma Outra Aprendizagem é Possível: colaboração em massa, recursos educacionais abertos e ensino de línguas. Disponível em: < http://www.scielo.br/pdf/tla/v55n2/0103-1813tla-55-02-00353.pdf>. Acesso em: 02 abr. 2017. 
MANZANERA, C. C. Diez ideas para aplicar el cine en el aula. Disponível em: < http://cvc.cervantes.es/ensenanza/biblioteca_ele/publicaciones_centros/pdf/manila_2009/16_a plicaciones_03.pdf >. Acesso em: 20 abril 2016.

OKADA, A. Recursos Educacionais Abertos \& Redes Sociais. São Luís: EDUEMA, 2014.

SANTOS; A. I. dos. Recursos Educacionais Abertos no Brasil: o estado da arte, desafios e perspectivas para o desenvolvimento e inovação. São Paulo: Comitê Gestor da Internet no Brasil, 2013.

SÃO PAULO. Governo Estadual de São Paulo. Assembleia Legislativa. Projeto de Lei Estadual $n^{\circ} 989$ de 14 de outubro de 2011. Institui política de disponibilização de Recursos Educacionais comprados ou desenvolvidos por subvenção da Administração Direta e Indireta Estadual. Diário Oficial do Estado de São Paulo. São Paulo, 2011.

XAVIER, A. C. Letramento Digital e Ensino. Disponível em:< http://www.ufpe.br/nehte/artigos/Letramento\%20digital\%20e\%20ensino.pdf>. Acesso em 20 mai 2017. 